\title{
Rapid prediction of 1-year efficacy of tofacitinib for treating refractory ulcerative colitis
}

\author{
Hiromichi Shimizu ${ }^{1}$, Toshimitsu Fujii ${ }^{1}$, Shuji Hibiya ${ }^{1}$, Maiko Motobayashi $^{2}$, Kohei Suzuki $^{3}$, Kento Takenaka ${ }^{2}$, \\ Eiko Saito ${ }^{1}$, Masakazu Nagahori ${ }^{1}$, Kazuo Ohtsuka ${ }^{2}$, Mamoru Watanabe ${ }^{4}$ \\ Departments of ${ }^{1}$ Gastroenterology and Hepatology, and ${ }^{2}$ Endoscopy, Tokyo Medical and Dental University, Tokyo, Japan; ${ }^{3}$ Department of \\ Internal Medicine, University of Texas Southwestern Medical Center, Dallas, TX, USA; ${ }^{4}$ Institute of Advanced Study, Tokyo Medical and Dental \\ University, Tokyo, Japan
}

Ulcerative colitis (UC) is an inflammatory bowel disease (IBD) characterized by chronic colon inflammation. The medications for UC include 5-aminosalicylic acid, corticosteroids, immunomodulators, and biologic agents. ${ }^{1}$ The latter two have been developing rapidly, and novel anti-tumor necrosis factor (TNF)- $\alpha$ agents have greatly improved outcomes for UC treatment refractory to conventional therapies. Other than biologic agents, tofacitinib (TOF) targets and blocks the Janus kinase pathway, a central hub in the cytokine network implicated in the modulation of immune and inflammatory responses. ${ }^{2}$ TOF has been effective for moderately to severely active UC in clinical trials, ${ }^{3-5}$ leading to its approval for UC treatment in 2018. However, real-world data from the clinical TOF application remains limited, especially regarding its clinical efficacy and safety. Herein, we present a short report on the real-world application of TOF on patients with refractory UC in our IBD center, focusing on long-term clinical efficacy and safety profiles.

We designed a retrospective observational study at the Tokyo Medical and Dental University (TMDU) hospital on Japanese patients under the care of board-certified gastroenterologists. We collected data on demographics, disease types, duration and activity, and treatment histories from patients with

Received February 24, 2020. Revised April 20, 2020. Accepted April 21, 2020 Correspondence to Hiromichi Shimizu, Department of Gastroenterology and Hepatology, Tokyo Medical and Dental University, 1-5-45 Yushima, Bunkyo-ku, Tokyo 113-8519, Japan. Tel: +81-3-5803-5877, Fax: +81-35803-0263,E-mail: hshigast@tmd.ac.jp
UC who had started TOF treatments between May and November 2018. The observation periods lasted up to 52 weeks after TOF administration. Patients were refractory to multiple treatments, such as corticosteroids, biologic agents, and a calcineurin inhibitor. TOF was initiated at $20 \mathrm{mg}$ a day and decreasing to $10 \mathrm{mg}$ a day after 8 weeks or more. All immunesuppressive agents, such as corticosteroids, immunomodulators, biologic agents, and calcineurin inhibitors, were withdrawn before starting TOF treatment. Disease activity was evaluated using the partial Mayo score (pMS), and laboratory data were collected at 4, 8, 12, 24, and 52 weeks after TOF administration. Our primary outcome was the clinical remission rate at 52 weeks; we also analyzed treatment efficacy and adverse events. We defined remission as $\mathrm{pMS} \leq 2$ without individual subscores $>1$, response as a decrease of pMS by at least 2 , and meeting one of the following conditions: (1) a decrease of the bleeding subscore by at least 1 ; (2) bleeding subscore $<1$; or (3) above-defined remission induced. ${ }^{6,7}$ Failure was defined as TOF discontinuation due to symptom recurrence in patients in remission, nonresponse to TOF treatment, and serious adverse events. ${ }^{8}$ Differences in medians between the groups were compared using a non-parametric (Mann-Whitney), and comparisons between categorical variables were performed using chi-square test. TOF discontinuation-free survival was calculated. Kaplan-Meier curves were drawn for each subgroup and compared with log-rank (Mantel-Cox) test. SPSS version 26 (IBM Corp., Armonk, NY, USA) was used for statistical analysis, and the significant threshold was 0.05 . 
The TMDU Institutional Review Board approved the study (IRB No. M2018-059). Informed consent was waived.

We enrolled 16 women (53.3\%) and 14 men (46.7\%) with a median age of 40.5 years (range, 28.3-60.0 years) and a median disease duration of 9.8 years (range, $6.5-11.8$ years). There were 18 patients $(60.0 \%)$ with extensive colitis and $12(40.0 \%)$ with left sided UC. In addition, 29 patients (96.7\%) showed moderate disease activity and 1 patient (3.3\%) showed mild UC, comprising a mean pMS of 6 points (range, 3-7 points). Most patients were corticosteroid refractory (46.7\%) or depen-

Table 1. Baseline Demographic and Disease Characteristics

\begin{tabular}{|c|c|}
\hline Variable & Value $(n=30)$ \\
\hline \multicolumn{2}{|l|}{ Sex } \\
\hline Female & $16(53.3)$ \\
\hline Male & $14(46.7)$ \\
\hline Age (yr) & $40.5(28.3-60.0)$ \\
\hline Disease duration (yr) & $9.8(6.5-11.8)$ \\
\hline \multicolumn{2}{|l|}{ Disease type } \\
\hline Extensive & $18(60.0)$ \\
\hline Left-sided & $12(40.0)$ \\
\hline \multicolumn{2}{|l|}{ Severity } \\
\hline Severe & 0 \\
\hline Moderate & $29(96.7)$ \\
\hline Mild & $1(3.3)$ \\
\hline Partial Mayo score & $6(3-7)$ \\
\hline Rachmilewitz endoscopic score $(n=14)$ & $8(8-10)$ \\
\hline White blood cells $\left(\times 10^{3} / \mu \mathrm{L}\right)$ & $6.1(5.3-8.7)$ \\
\hline Hemoglobin (g/dL) & $12.9(11.8-14.0)$ \\
\hline Albumin (g/dL) & $3.9(3.4-4.3)$ \\
\hline $\mathrm{CRP}(\mathrm{mg} / \mathrm{dL})$ & $0.2(0.0-0.8)$ \\
\hline $\mathrm{ESR}(\mathrm{mm} / \mathrm{hr})$ & $16.5(5.8-29.8)$ \\
\hline Use of 5-ASA & $16(53.3)$ \\
\hline \multicolumn{2}{|l|}{ Corticosteroid } \\
\hline Refractory & $14(46.7)$ \\
\hline Dependent & $14(46.7)$ \\
\hline Use of immunomodulator & $14(46.7)$ \\
\hline Previous anti-TNF- $\alpha$ agent failure & $29(96.7)$ \\
\hline 1 Agent & $15(50.0)$ \\
\hline 2 Agents & $13(43.3)$ \\
\hline 3 Agents & $1(3.3)$ \\
\hline Previous calcineurin inhibitor failure & $11(36.6)$ \\
\hline
\end{tabular}

Values are presented as number (\%) or median (range).

CRP, C-reactive protein; ESR, erythrocyte sedimentation rate; 5-ASA, 5aminosalicylic acid; TNF, tumor necrosis factor. dent (46.7\%) and unresponsive to one or more anti-TNF- $\alpha$ agents (96.7\%). Moreover, $36.6 \%$ patients were unresponsive to a calcineurin inhibitor (Table1). Patients were monitored for up to 52 weeks ( 14 patients were monitored until 52 weeks), and the median follow-up period was 23.0 weeks (range, 4.052.0 weeks). At 4 weeks of TOF treatment, 12 patients (40.0\%) responded to the medication, and $6(20.0 \%)$ achieved remission. Both the response and remission rates continued to exceed $40 \%$ from 8 to 52 weeks of TOF treatment (Fig. 1A). At 52 weeks, 12 patients were in remission, 1 patient who had achieved remission experienced slight worsening without requiring TOF discontinuation, and 16 patients experienced treatment failure, of which 13 were nonresponsive and 3 developed recurrence. At 52 weeks, the responders showed significantly improved pMS from as early as 4 weeks after TOF administration, which continued to improve until 52 weeks. Overall, 91.7\% (95\% confidence interval [CI], 83.7\%-99.7\%) TOF responders at 4 weeks were able to continue the treatment for 52 weeks. However, 80.0\% (95\% CI, 70.1\%-89.9\%) of
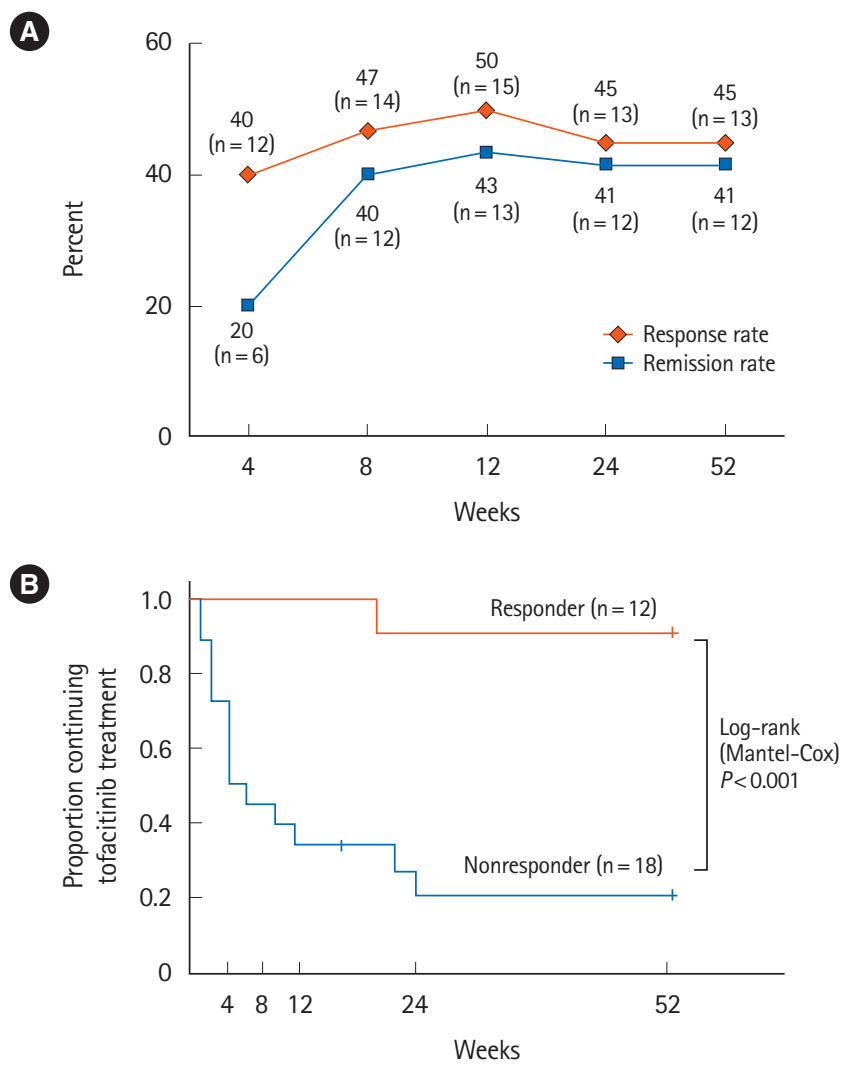

Fig. 1. Efficacy of tofacitinib. (A) Response and remission rates at 4 weeks were $40 \%$ and $20 \%$, respectively, and both rates exceeded 40\% from 8 to 52 weeks. (B) Responders at 4 weeks had significantly less discontinuation of tofacitinib until 52 weeks. 
TOF nonresponders at 4 weeks discontinued TOF treatment due to lack of efficacy (Fig. 1B). The background characteristics of TOF responders and nonresponders at 4 weeks were similar without any significant difference, except in terms of

Table 2. Background Characteristics of 4-Week Responders and Nonresponders

\begin{tabular}{|c|c|c|c|}
\hline Variable & $\begin{array}{l}\text { Responder } \\
(n=12)\end{array}$ & $\begin{array}{l}\text { Nonresponder } \\
(n=18)\end{array}$ & $P$-value \\
\hline Sex & & & 0.45 \\
\hline Female & $5(41.7)$ & $11(61.1)$ & \\
\hline Male & $7(58.3)$ & $7(38.9)$ & \\
\hline Age (yr) & $46.0(37.3-60.0)$ & $35.0(25.6-47.8)$ & 0.23 \\
\hline Disease duration (yr) & $9.5(8.0-14.5)$ & $7.0(4.3-11.0)$ & 0.10 \\
\hline \multicolumn{4}{|l|}{ Disease type } \\
\hline Extensive & $6(50.0)$ & $12(66.7)$ & 0.46 \\
\hline Left-sided & $6(50.0)$ & $6(33.3)$ & 0.71 \\
\hline Severity & & & 0.40 \\
\hline Severe & 0 & 0 & \\
\hline Moderate & $12(100)$ & $17(94.4)$ & \\
\hline Mild & 0 & $1(5.6)$ & \\
\hline Partial Mayo score & $5.5(3.0-6.0)$ & $6.0(4.0-7.0)$ & 0.36 \\
\hline $\begin{array}{l}\text { Rachmilewitz } \\
\text { endoscopic score } \\
(n=14)\end{array}$ & $8.0(7.0-9.0)$ & $8.0(8.0-9.0)$ & 0.53 \\
\hline $\begin{array}{l}\text { White blood cells } \\
\qquad\left(\times 10^{3} / \mu \mathrm{L}\right)\end{array}$ & $5.5(5.6-6.0)$ & $7.3(5.9-9.3)$ & 0.06 \\
\hline Hemoglobin (g/dL) & $12.8(12.4-13.2)$ & 13.1 (10.4-14.0) & 0.98 \\
\hline Albumin (g/dL) & $3.9(3.5-4.1)$ & $4.0(3.3-4.3)$ & 0.98 \\
\hline $\mathrm{CRP}(\mathrm{mg} / \mathrm{dL})$ & $0.2(0.1-0.3)$ & $0.3(0.1-1.6)$ & 0.31 \\
\hline $\mathrm{ESR}(\mathrm{mm} / \mathrm{hr})$ & $17.0(12.0-23.0)$ & $16.5(7.5-26.3)$ & 0.83 \\
\hline Use of 5-ASA & $6(50.0)$ & $5(27.8)$ & 0.77 \\
\hline \multicolumn{4}{|l|}{ Corticosteroid } \\
\hline Refractory & $5(41.7)$ & $9(50.0)$ & 0.72 \\
\hline Dependent & $6(50.0)$ & $8(44.4)$ & 0.77 \\
\hline $\begin{array}{l}\text { Use of } \\
\text { immunomodulator }\end{array}$ & $5(41.7)$ & $9(50.0)$ & 0.66 \\
\hline $\begin{array}{l}\text { Previous anti-TNF- } \alpha \\
\text { agent failure }\end{array}$ & $12(100)$ & $17(94.4)$ & 0.72 \\
\hline 1 Agent & $7(58.3)$ & $8(44.4)$ & 0.71 \\
\hline 2 Agents & $5(41.7)$ & $8(44.4)$ & 0.88 \\
\hline 3 Agents & 0 & $1(5.6)$ & 0.41 \\
\hline $\begin{array}{l}\text { Previous calcineurin } \\
\text { inhibitor failure }\end{array}$ & $2(16.7)$ & $9(50.0)$ & 0.02 \\
\hline
\end{tabular}

Values are presented as number (\%) or median (range).

CRP, C-reactive protein; ESR, erythrocyte sedimentation rate; 5-ASA, 5-aminosalicylic acid; TNF, tumor necrosis factor. previous calcineurin inhibitor failure (Table 2). For the safety evaluation, the most common adverse events were non-serious infections $(\mathrm{n}=9,30.0 \%)$. Three patients (10.0\%) presenting herpes zoster infections were treated successfully with anti-viral medication. One patient, a 60-year-old male using $20 \mathrm{mg}$ TOF, developed herpes zoster at 16 weeks, and others, a 67-year-old male and a 40-year-old female using $10 \mathrm{mg}$ TOF, developed herpes zoster at 24-25 weeks; all patients presented a history of previous corticosteroid exposure, although not at the time of infection. Also, 4 patients (13.3\%) started medication for dyslipidemia. No serious adverse events were recorded, and no adverse events resulted in discontinuation of TOF treatment (Supplementary Table 1).

In here, we present a preliminary report on the clinical efficacy and safety of TOF treatment for refractory UC, a treatment at an early stage of real-world application. Although the full breadth of the clinical implications and safety profiles of this treatment remain unclear, Lair-Mehiri et al. ${ }^{9}$ have just reported on real-world experience with TOF, in which the efficacy of TOF was $>30 \%$ at 48 weeks and more than half of the patients could continue TOF treatment for 48 weeks, avoiding colectomy. We showed consistent efficacy of TOF in that $40.0 \%$ patients were responsive and $20.0 \%$ in remission at 4 weeks, and both rates continued to exceed $40 \%$ from 8 to 52 weeks. LairMehiri et al. ${ }^{9}$ have also highlighted the safety profile of TOF, stating that it is safe enough for outpatient use, and our data hopefully supports their data. Although, we encountered nonserious adverse events associated with TOF treatment, some serious adverse events have been reported in TOF users with rheumatoid arthritis since $2012 .^{10}$ It is not the same case for patients with UC as their background is different from that of patients with rheumatoid arthritis. However, patients with IBD are at a certain risk of deep vein thrombosis; thus, it is very important to account for cardiovascular risks when using TOF for patients with UC and further extensive analyses are needed. Our data showed that, at 4 weeks, most TOF responders could continue the treatment for 52 weeks, exhibiting a continued positive response with no serious adverse events. This suggests that predicting long-term TOF efficacy after 4 weeks of treatment is possible, allowing for a quick and efficient clinical decision as to whether continue or discontinue the TOF treatment. We are aware that our small sample cohort, distinct patient population, 1-year of follow-up, and single center evaluation represent substantial study limitations, but our report provides new information on real-world TOF treatment for patients with refractory UC. 


\section{ADDITIONAL INFORMATION}

\section{Funding Source}

The authors received no financial support for the research, authorship, and/or publication of this article.

\section{Conflict of Interest}

Research Grants/Clinical Trial Funding: AbbVie (Fujii T, Watanabe M), Boehringer Ingelheim (Fujii T, Watanabe M), Celgene (Fujii T, Watanabe M), EA Pharma (Fujii T, Watanabe M), Eisai (Fujii T, Watanabe M), Gilead Sciences (Fujii T, Watanabe M), Eli Lilly (Fujii T, Watanabe M), Mitsubishi Tanabe Pharma (Watanabe M). Consultancy: Kissei Pharma (Nagahori M), Takeda (Nagahori M); Speaker's Bureau: AbbVie (Fujii T, Nagahori M, Ohtsuka K), Ajinomoto Pharma (Fujii T, Watanabe M), Boehringer Ingelheim (Fujii T), Daiichi Sankyo (Fujii T), EA Pharma (Fujii T), Kyorin Pharma (Fujii T, Watanabe M), Kyowa Hakko Kirin (Fujii T), BMS (Fujii T), Nichiiko (Fujii T), Mitsubishi Tanabe Pharma (Takenaka K, Nagahori M, Watanabe M, Ohtsuka K), Kyorin (Takenaka K, Fujii T, Nagahori M, Watanabe M, Ohtsuka K), Mochida Pharma (Takenaka K, Watanabe M, Ohtsuka K), Nippon Kayaku (Fujii T, Nagahori M, Watanabe M), Kissei Pharma (Fujii T, Nagahori M), Asashi Kasei (Nagahori M), Zeria Pharma (Takenaka K, Fujii T, Nagahori M, Ohtsuka K), Astellas Pharma (Nagahori M), and Janssen Pharma (Fujii T, Nagahori M, Watanabe M). The remaining authors have no conflicts to disclose.

Watanabe $\mathrm{M}$ is an editorial board member of the journal but did not involve in the peer reviewer selection, evaluation, or decision process of this article. No other potential conflicts of interest relevant to this article were reported.

\section{Author Contribution}

Conception and design of study: Shimizu H, Fujii T, Watanabe M. Drafting of manuscript: Shimizu H. Analysis and acquisition of data: Shimizu H. Statistical analysis: Shimizu H, Hibiya S. Approval of the final version of the manuscript: all authors.

\section{ORCID}

Shimizu H

Fujii T

Hibiya S

Motobayashi M

Suzuki K

Takenaka K
Saito E

Nagahori M

Ohtsuka K

Watanabe M

https://orcid.org/0000-0002-4806-130X https://orcid.org/0000-0002-5323-7058

https://orcid.org/0000-0002-2409-9709

https://orcid.org/0000-0002-5475-9544

\section{Supplementary Material}

Supplementary materials are available at the Intestinal Research website (https://www.irjournal.org).

\section{REFERENCES}

1. Ordás I, Eckmann L, Talamini M, Baumgart DC, Sandborn WJ. Ulcerative colitis. Lancet 2012;380:1606-1619.

2. Danese S, Grisham M, Hodge J, Telliez JB. JAK inhibition using tofacitinib for inflammatory bowel disease treatment: a hub for multiple inflammatory cytokines. Am J Physiol Gastrointest Liver Physiol 2016;310:G155-G162.

3. Sandborn WJ, Su C, Sands BE, et al. Tofacitinib as induction and maintenance therapy for ulcerative colitis. N Engl J Med 2017;376:1723-1736.

4. Sandborn WJ, Panés J, D'Haens GR, et al. Safety of tofacitinib for treatment of ulcerative colitis, based on 4.4 years of data from global clinical trials. Clin Gastroenterol Hepatol 2019; 17:1541-1550.

5. Suzuki Y, Watanabe M, Matsui T, et al. Tofacitinib as induction and maintenance therapy in Japanese patients with active ulcerative colitis. Inflamm Intest Dis 2019;4:131-143.

6. Rutgeerts P, Sandborn WJ, Feagan BG, et al. Infliximab for induction and maintenance therapy for ulcerative colitis. N Engl J Med 2005;353:2462-2476.

7. Schroeder KW, Tremaine WJ, Ilstrup DM. Coated oral 5-aminosalicylic acid therapy for mildly to moderately active ulcerative colitis: a randomized study. N Engl J Med 1987;317:16251629.

8. D'Haens G, Sandborn WJ, Feagan BG, et al. A review of activity indices and efficacy end points for clinical trials of medical therapy in adults with ulcerative colitis. Gastroenterology 2007; 132:763-786.

9. Lair-Mehiri L, Stefanescu C, Vaysse T, et al. Real-world evidence of tofacitinib effectiveness and safety in patients with refractory ulcerative colitis. Dig Liver Dis 2020;52:268-273.

10. Wollenhaupt J, Lee EB, Curtis JR, et al. Safety and efficacy of tofacitinib for up to 9.5 years in the treatment of rheumatoid arthritis: final results of a global, open-label, long-term extension study. Arthritis Res Ther 2019;21:89. 
See "Rapid prediction of 1-year efficacy of tofacitinib for treating refractory ulcerative colitis" on page 115 -118.

Supplementary Table 1. Adverse Events during Tofacitinib Administration

\begin{tabular}{lc}
\hline Variable & No. (\%) $(n=30)$ \\
\hline Infectious adverse events & $9(30.0)$ \\
Herpes zoster & $3(10.0)$ \\
Upper respiratory tract infection & $2(6.7)$ \\
Paranasal sinusitis & $2(6.7)$ \\
External otitis & $1(3.3)$ \\
Serpigo & $1(3.3)$ \\
Dyslipidemia & $4(13.3)$ \\
Acne & $1(3.3)$ \\
Serious adverse events & 0 \\
\hline
\end{tabular}

